
\title{
25 Research Square \\ Factors affecting root migration after coronectomy of the mandibular third molar
}

\author{
Nan-ju Lee \\ Yonsei University College of Dentistry \\ Seo-Yeon Jung \\ Yonsei University College of Dentistry \\ Kyeong-Mee Park \\ Yonsei University College of Dentistry \\ Yiseul Choi \\ Yonsei University College of Dentistry \\ Jisun Huh \\ Yonsei University College of Dentistry \\ Wonse Park ( $\nabla$ wonse@yuhs.ac )
}

Yonsei University College of Dentistry https://orcid.org/0000-0002-2081-1156

\section{Research article}

Keywords: Inferior alveolar nerve, Third molar, Nerve injury, Coronectomy, Cone-beam computed tomography

Posted Date: July 21 st, 2020

DOI: https://doi.org/10.21203/rs.3.rs-37111/v2

License: (c) (i) This work is licensed under a Creative Commons Attribution 4.0 International License. Read Full License

Version of Record: A version of this preprint was published at Medicine on May 21st, 2021. See the published version at https://doi.org/10.1097/MD.0000000000025974. 


\section{Abstract}

Background The purpose of this study was to analyze root migration and its influencing factors at 6 months after coronectomy in both two- and three-dimensions using periapical view and cone-beam computed tomography (CBCT).

Methods Thrity-three cases of root remnant after coronectomy were included and analyzed. We measured the amount of migration in CBCT. The following factors that could possibly affect root migration were also analyzed: age, gender, number of mandibular third molar (M3) roots, shape of M3s, Pell and Gregory classification, mesiodistal (MD) angulation, buccolingual (BL) angulation, contact point with the second molar, root curvature, and complete removal of the coronal portion.

Results Migration of greater than $2 \mathrm{~mm}$ was found in $64 \%$ of the roots in the $2 \mathrm{D}$ analysis, and the average root migration was $4.11 \mathrm{~mm}$ in the 3D analysis. The factors affecting migration were the root morphology, complete removal of the coronal portion, impaction depth, and $\mathrm{MD}$ angulation in the $2 \mathrm{D}$ analysis, and $\mathrm{MD}$ and $\mathrm{BL}$ angulation in the $3 \mathrm{D}$ analysis.

Conclusion In conclusion, complete removal of the coronal portion and ensuring sufficient space for root migration might be important factors after coronectomy of the M3.

Clinical relevance Root remnant after coronectomy of M3 may migrate in young patients who has sufficient empty coronal space and this may reduce the nerve damage by the separation of IAN and M3.

\section{Background}

Extraction of the mandibular third molar (M3) is a most common surgical procedure performed in the dental clinic. When extracting a mandibular $\mathrm{M} 3$, an exact assessment of the spatial relationship between the inferior alveolar nerve (IAN) and mandibular M3 is necessary to prevent damaging the IAN. The reported incidence of IAN paresthesia after M3 extraction has varied widely, from $0.35 \%$ to $8.4 \%[1,2]$.

Cone-beam computed tomography (CBCT) is now widely used in dental clinics, especially to evaluate the three-dimensional (3D) relationship between the IAN and M3 to predict the risk of nerve injury [3]. Coronectomy was introduced as an alternative method for decreasing the risk of IAN injury in high-risk patients [4]. However, some limitations of coronectomy have appeared, such as the long-term fate of the remnant roots and the risk of infection associated with pulp necrosis, which have resulted in coronectomy being considered an unacceptable alternative to conventional odontectomy [5].

This controversial situation has prompted numerous studies, with the results showing that compared to conventional extraction of the mandibular M3, performing a coronectomy in which only the crown of the tooth is removed and the roots are left in place decreases the risk of nerve injury [6-9]. In addition to the safety and effectiveness of coronectomy, some studies have analyzed the migration of the remnant roots, and found that their migration pattern may be affected by factors such as the patient age, sex, 
impaction depth, angulation, and eruption status [10-12]. However, these studies used only twodimensional (2D) analysis to detect root migration and did not involve removing the remnant roots.

The purpose of this study was to analyze root migration and its influencing factors at 6 months after coronectomy until their removal in two and three dimensions using CBCT.

\section{Methods}

\section{Study design}

This study was approved by the Institutional Review Board of Yonsei University, Seoul, South Korea (IRB number: 2-2018-0038). This retrospective study included patients who visited the Department of Advanced General Dentistry at Yonsei University Dental Hospital from January 1, 2016 to December 31, 2018 for the removal of one or more mandibular M3s. X-rays were taken (including panoramic radiographs and periapical radiographs) of the mandibular M3s in order to evaluate the difficulty of the extraction and the risk of IAN injury. The high-risk patients with one or more radiographic signs showing close proximity of the mandibular M3 roots to the IAN in their preoperative panoramic radiographs also underwent $\mathrm{CBCT}$ for evaluating the spatial relationships [13-15]. The radiographic risk signs were (1) darkening of M3 roots, (2) deflection of M3 roots, (3) abrupt narrowing of M3 roots, (4) M3 roots with a dark and bifid apex, (5) interruption and loss of the white line(s) of the inferior alveolar canal (IAC), (6) diversion or displacement of the IAC(s) by the roots, (7) abrupt narrowing of one or both of the canal white lines representing the IAC(s), and (8) the presence of superposition.

Patients in whom the root was in direct contact with the IAN or the IAN was compressed in CBCT images were informed about the risks, benefits, and potential complications of both complete removal of M3 and coronectomy $[11,16]$. After they adequately understood the two different surgical techniques, 39 patients (51 mandibular M3s) agreed to undergo coronectomy, and they were instructed to return for postoperative follow-up visits at 1 month, 3 months, and 6 months after the coronectomy. Periapical radiographs were taken at every visit in order to check the status of the root remnant, and CBCT was performed after 6 months to verify the movement of the remnant root, at which time the risks and benefits of removing the root remnant was explained to the patients. Except 11 patients (16 mandibular M3s), who lost to follow-up visits or did not want to remove the remnant roots in their own reasons, we included 28 patients (35 mandibular M3s) in this study (Fig. 1). They attended regular follow up visits and root migration was confirmed on their CBCT images taken at 6 months after coronectomy. In those cases, we suggested root removal to patients and all 28 patients agreed to remove the remnant roots.

\section{Surgical procedures}

All patients were instructed to take prophylactic antibiotics and an non-steroidal anti-inflammatory drug 1 hour before the surgery $[17,18]$. All surgeries were performed by the same surgeon and the surgical procedures were performed under sufficient local anesthesia (lidocaine $2 \%$ with 1:100,000 epinephrine). A mucoperiosteal flap was incised and elevated, and the bone was removed with a fissure bur until the 
cementoenamel junction of M3 was exposed $[19,20]$. Sectioning was performed along the cementoenamel junction using a fissure bur, and the cutting surface was trimmed with a round bur in order to equalize the sectioning level [19]. Finally, after ensuring that the cut margin was at least $3 \mathrm{~mm}$ below the alveolar bone level, the wound was thoroughly irrigated with saline and sutured primarily without any pulp treatment $[9,11]$. Panoramic and periapical radiography and CBCT were performed immediately postoperatively to check the sectioned surface and to record the postoperative position of the remnant roots. Routine antibiotic and NSAID were prescribed for 3 days, and postoperative precautions were explained to all patients. At 1 day after the surgery, patients were recalled checking the postoperative pain level and dress the wound. All symptoms and complications were recorded. The stitches were removed from all patients 1 week after the procedure.

\section{Measurements}

2D analysis was performed using the obtained periapical radiographs. On 6-month follow-up periapical radiographs we measured the distance between the original and 6 months after coronectomy traces of the lamina dura of the root apex. This measurement was made twice, and the mean distance was recorded. Cases with migration distances exceeding $2 \mathrm{~mm}$ and up to $2 \mathrm{~mm}$ were classified into 2D migration and no-migration groups, respectively $[12,21]$. Three-dimensional (3D) analysis was applied to the reconstructed $\mathrm{CBCT}$ images using a program for 3D reconstruction (OnDemand, Cybermed, Korea). Each measurement was made twice: the first on the CBCT scan obtained preoperatively and the second on the CBCT scan obtained immediately before removing the remnant roots [22]. All measurements were made by the same inspector. The 3D spatial vector was set using the following anatomical reference points: mandibular interincisal tip, mandibular right and left canine tips, and the mesiobuccal cusp tip of the mandibular first molar. The axes were set automatically by the OnDemand program using the selected reference points, and the mandibular interincisal tip was set as the origin. Each axis represented different vectors, with the $\mathrm{X}-, \mathrm{Y}$-, and $\mathrm{Z}$-axes representing buccolingual (BL), anteroposterior, and superioinferior movements, respectively. In addition, two points were identified to represent the remnant roots: MR (the most-apical point on the mesial root, or mesiobuccal roots if there were two roots on mesial) and DR (the most-apical point on the distal root). The coordinates of these two points were obtained, and the migration distances were measured by calculating the point-to-point differences between the primary and secondary coordinates (Fig 2).

\section{Statistical analysis}

Statistical analyses were performed to analyze the migration distances according to the various possible influencing factors and to find the correlations between them. The t-test and ANOVA were used to investigate the relationships between/among subgroups, and binary logistic regression and multivariate linear regression were used to identify the influencing factors in both the 2D and 3D analyses. Furthermore, we used parametric Pearson correlation analysis to identify the correlation between migration and a specific axis. Differences were considered statistically significant at $P<0.05$. All statistical analyses were performed using IBM SPSS Statistics software (version 25). 


\section{Results}

Study sample and classifications (Table 1, Appendix figure 1)

35 cases in which the remnant roots were removed after coronectomy (28 patients: 10 males and 18 females) were measured using both 2D and 3D analyses. But 2 cases were excluded due to the loss of the CBCT scans obtained immediately before root removals and 33 cases were included and analyzed finally. The patients were aged $27.1 \pm 6.2$ years (mean \pm SD, range $20-47$ years) and the average followup period before root removal was 5.7 months (range 4-12 months). Of all 33 cases, 4 cases were performed far from the average follow up period. 2 cases in same person are performed at 4 months because patient wanted to remove the roots early and other 2 cases are performed at 10,12 months each due to loss of their 6 month follow up visits. We included those cases because root migration was confirmed evidently compared with their CBCT taken at the last visits. No postoperative complications including infection or injury of the IAN or lingual nerve were reported. The demographic data of the patients and the results of analyzing the influencing factors based on the status and radiographic signs of the mandibular M3 and the distribution of cases are presented in Table 1 [23-25].

\section{Root migration in 2D analysis (Table 2)}

The 33 cases measured in 2 dimensions comprised 21 in the migration group and 12 in the no-migration group; that is, about two-thirds (64\%) of the remnant roots migrated more than $2 \mathrm{~mm}$ in the 2D analysis. When we investigated the correlation between migration in the 2D analysis and each influencing factor without adjusting for the effects of other factors, only BL angulation significantly affected migration $(P=0.002)$. After adjusting all of the factors that could influence root migration using binary logistic regression with a backward method, we obtained an optimal model to explain root migration in the 2D analysis. According to this model, MD angulation, impaction depth, root form, and cutting completeness significantly affected root migration $(P<0.05)$, and the odds ratios were calculated for all of the factors. These values could be used to predict the likelihood of the root migrating after coronectomy in the 2D analysis. For example, the likelihood of migrating would increase if the mandibular M3 was impacted horizontally rather than vertically, the impaction depth was superior rather than inferior, the root form was convergent rather than divergent, and cutting was performed completely rather than incompletely.

\section{Root migration in 3D analysis (Table 3)}

The migration distance measured using the 3D method was $4.11 \pm 1.50 \mathrm{~mm}$ (range $0.72-9.38 \mathrm{~mm}$ ), which meant that the remnant roots migrated somewhat from their preoperative positions. However, this did not mean that all roots migrated forward and upward from their original positions, as we had expected [9]. This finding prompted us to divide the migration direction into those in the $\mathrm{X}-, \mathrm{Y}-$-, and Z-axis directions, with that along each axis investigated to confirm the correlation with the average distance. The migration distances along all axes were moderately correlated with the average migration distance, with Pearson correlation coefficients ( $r$ ) of $0.484,-0.542$, and 0.301 for the $X-, Y$-, and Z-axes, respectively. There was a statistically significant $(P<0.05)$ correlation between the migration distances along the $X$ - 
and $\mathrm{Y}$-axes [26], meaning that the general migration direction of the remnant roots was along the $\mathrm{BL}$ and anteroposterior axes. None of the other factors significantly affected the migration distance in the 3D analysis $(P>0.05)$. After adjusting for all factors that could influence root migration using multivariate linear regression with a stepwise method, only MD angulation, $\mathrm{BL}$ angulation, and $\mathrm{Y}$-axis migration distance significantly affected the average 3D migration distance. Accordingly, we could quantify the average migration distance in the 3D analysis as $3.581+(-0.582)^{\prime}(Y$-axis migration distance $)+(-$ $1.540)^{\prime}(\mathrm{BL}$ angulation $)+1.855^{\prime}(\mathrm{MD}$ angulation [vertical / horizontal]). For example, when the mandibular M3 impacted lingually rather than buccally and vertically rather than horizontally, the average migration distance would increase. Also, because negative $Y$ values indicated frontward movement of the remnant roots, the average migration distance would increase if the remnant roots migrated more in a frontward direction.

\section{Discussion}

Coronectomy is considered an alternative method of preventing nerve damage to M3s close to the IAN, but many issues about this procedure remain controversial [27]. In particular, because the residual roots are buried in the jaw, they can induce inflammation, cysts, and benign tumors [28]. The main controversy relates to leaving a residual root for a long time. The ability to predict root movement after coronectomy would make it possible to predict how far away M3 and the IAN will be after coronectomy. If these two structures are separated after coronectomy, a two-stage approach involving coronectomy and removal of the remaining root after coronectomy might be less likely to cause nerve damage.

This study aimed to determine the movement of the roots left after coronectomy using both 2D and 3D analyses.

In the 2D analysis, we obtained periapical radiographs immediately and 1 month, 3 months, and 6 months after coronectomy in order to observe whether root movement or inflammatory changes occurred. We found that $64 \%$ of the roots ( 21 of 33 cases) had migrated more than $2 \mathrm{~mm}$ at 6 months after coronectomy, and that there were no cases of the two structures coming closer together. That result is similar with Leung and Cheung studies that said $62.2 \%$ of cases presented root migrations at 6 months after coroenctomy and mean movement was $2.33 \mathrm{~mm}$ [2].

While a periapical radiograph is a good evaluation method due to the low radiation dose, it is difficult to make an accurate judgment due to the presence of superposition, errors depending on the viewing angle, and tendency for enlargement. Since the present analysis was performed up to 6 months postoperatively, it was possible to determine whether movement occurred. However, determining the direction of movement in three dimensions and separating the root from the IAN requires a dental CBCT scan to identify the risks and benefits of leaving or removing residual roots after 6 months. We therefore additionally performed CBCT and 3D analysis in the patients who agreed for the roots to be removed. The mean migration distance after 6 months in the 3D analysis was $4.11 \mathrm{~mm}$, which is greater than in previous studies $[11,12,29,30]$. 
There are already many studies which analyzed root migration and affecting factors using CBCT cross section. Especially, Goto et al (2012) reported the average length of migration was $3 \mathrm{~mm}$ and Yeung et al (2018) reported that the mean migration distance was $2.82 \mathrm{~mm}$ and remnant roots predominantly translated mesialy. The most important difference between our study and the previous studies is that, instead of using CBCT cross section, we set axes and applied coordinations in order to calculate migration distance and investigate direction 3 dimensionally $[29,30]$. Also, one more difference is that we removed the residual roots at about 6 months after coronectomy. Although the follow-up period of studies has varied, it is commonly reported that root migration after coronectomy mostly occurs within the first year, and especially within the first 6 months [12]. Leung and Cheung (2018) reported that the rate of root migration was highest during the first 6 months after coronectomy, while Kohara et al. (2015) reported active root migration and bone formation over the resected surface during the first year after coronectomy, after which root migration eventually stabilized.

We found that the migration distance of the residual roots was affected by various factors. It was found that root morphology, cutting completeness, impaction depth, and MD angulation were related in the $2 \mathrm{D}$ analysis, and that $M D$ and $B L$ angulation were related in the group in which the residual root and IAN were found to be separated in the 3D analysis.

In terms of angulation, horizontal and mesial impactions were more mobile than vertical and distal impactions. The possible cause is the horizontal and mesial impactions having a large space into which the root can move after coronectomy, whereas that for vertical and distal angulation is relatively small. Also, that space formed between the distal surface of the second molar and remnant roots is not covered by new bone because of consistent infection by food debris and irritants in the mouth and soft-tissue scar. In our cases we observed new bone formation above the surface cut in the coronectomy in vertical and distal impactions and found a lower migration tendency than for horizontal and mesial impaction in both the 2D and 3D analyses (Appendix figure 2).

The impaction depth also showed similar results and so similar assumptions can be made. If there was sufficient space for the root to move after coronectomy, there was a large amount of movement. However, in our 2D analysis we observed that deeper impaction was associated with a greater tendency for new bone to form above the cut surface combined with less migration.

The surgical technique also affected the amount of root movement, which was small when the crown was not completely removed. In other words, even if there is a lot of space (e.g., in the mesial or horizontal direction) due to the cutting being performed incorrectly, the root can still be physically prevented from moving during eruption (Appendix figure 3). The convergent root form also showed a greater migration tendency than divergent roots, which can be easily understood from a morphological point of view.

In summary, being physical prevented from moving is expected to have the greatest effect on root movement considering the angulation, impaction depth, surgical technique, and root morphology. 
One especially interesting finding was of the curved root-two cases where the roots were severely curved and close to each other were observed in this study. Even in such cases, it is assumed that root movement can occur if there is space in which the root can move after coronectomy. Root curvature is important when M3 extraction is planned. A curved root can be easily broken during extraction, and there is a possibility that the remaining broken root will continuously irritate the lower alveolar canal, requiring another procedure to remove the broken residual root, which can cause nerve damage. Our results suggest that coronectomy can be considered in cases of a curved root that is close to the IAC because the curvature of the root results in the root not being immobile (Appendix figure 4).

The remnant root migrates through bone after coronectomy remains unclear. Possible mechanisms include (1) the exerting of forces that are similar to those that cause tooth eruption, which derive from active metabolism in the periodontal ligament [31], and (2) the removal of mechanical interferences along the eruption path, which induces spontaneous eruption into the free space [32]. For example, a tooth can over erupt until it reaches an interference such as an opposed ridge or soft tissue when the opposing tooth is missing in clinical situations. Therefore, if there are no mechanical interferences to erupt or they are removed by coronectomy, the remnant roots could migrate through the free space. Further studies in animals and histological examinations are needed to satisfactorily explain the migration of remnant roots.

The first limitation of this study was the small total number of cases $(n=33)$, which prevented appropriate statistical analyses such as comparisons of the horizontal, mesial, vertical, and distal angulations. Second, the need for two surgeries to remove the cause of the infection is also a disadvantage of this treatment method. Third, the surgery was performed by a single operator, and so data from a multicenter study involving various surgeons might be more reliable. Fourth, 54.5\% of cases were performed incomplete cutting which was inconsistent with our discussion. We tried to section the M3s along the cementoenamel junction in order to being not remained retained enamel which is not sterile and inhibits the adhesion of regenerating bone $[33,34]$. However, several factors such as impaction angle, depth and adjacent teeth disturbed clear sights and approach during the surgical procedures. And the last, we decided and suggested root removal confirming the root migration at 6 months after coronectomy. Pogrel et al considered all the indicators tended to be relatively stable after 6 months and that longer follow up was not required and Kang et al said root fragments had migrated more quickly in the first 6 months and remained stable after 12 months as bone deposition and connective tissue coverage occurred which requires additional bone reduction. According to those studies, we thought 6 months follow up is enough to evaluate root migration and decide root removal in order to avoid extensive surgery.

\section{Conclusion}

In conclusion, complete removal of the coronal portion and sufficient space for root migration might be important influencing factors after coronectomy of the mandibular M3.

\section{Declarations}




\section{Acknowledgements}

Not applicable

\section{Author's contributions}

All authors actively participate in the study and made substantial contributions to this article. Nan-Ju Lee contributed to conception, design, data acquisition, analysis and interpretation, drafted manuscript: SeoYeon Jung contributed to conception and analysis, drafted manuscript, and critically revised the manuscript; Kyeong-Mee Park contributed to design and data acquisition, and critically revised the manuscript; Yiseul Choi contributed to design and data acquisition, and critically revised the manuscript; Jisun Huh contributed to conception and interpretation, and critically revised the manuscript; Wonse Park contributed to conception, design, data analysis and interpretation, critically revised the manuscript. All authors gave their final approval and agree to be accountable for all aspects of work ensuring integrity and accuracy.

\section{Funding}

This research was supported by the Basic Science Research Program through the National Research Foundation of Korea (NRF) funded by the Ministry of Education (grant no. 2017R1D1A1B03033657).

The funders were not involved with the design or conduct of the study; collection, management, analysis or interpretation of the data; preparation, review or approval of the manuscript; or decision to submit the manuscript for publication.

\section{Availability of data and materials}

The raw data are confidential and cannot readily be shared. Researchers need to obtain permission from the Institutional Review Board and apply for access to the data from the Yonsei university Dental Hospital.

\section{Ethics approval and consent to participate}

This study protocol was approved by the Institutional Review Board of Yonsei University, Seoul, South Korea (IRB number: 2-2018-0038). The study was designed as a retrospective study and all participants consent was waived for this study. All data were anonymized to ensure the confidentiality of the participants

\section{Consent to publications}

Not applicable

\section{Competing interests}

All authors declare that we do not have any potential conflicts of interests in this study. 


\section{Abbreviations}

M3: mandibular third molar, CBCT: cone-beam computed tomography, IAN: inferior alveolar nerve, IAC: inferior alveolar canal , MD: mesiodistal, BL: buccolingual, 2D: 2 dimensional, 3D: 3 dimensional

\section{References}

1. Sarikov R, Juodzbalys G: Inferior alveolar nerve injury after mandibular third molar extraction: a literature review. J Oral Maxillofac Res 2014, 5(4):e1.

2. Leung YY, Cheung LK: Safety of coronectomy versus excision of wisdom teeth: a randomized controlled trial. Oral Surg Oral Med Oral Pathol Oral Radiol Endod 2009, 108(6):821-827.

3. Pohlenz P, Blessmann M, Blake F, Heinrich S, Schmelzle R, Heiland M: Clinical indications and perspectives for intraoperative cone-beam computed tomography in oral and maxillofacial surgery. Oral Surg Oral Med Oral Pathol Oral Radiol Endod 2007, 103(3):412-417.

4. Pogrel MA, Lee JS, Muff DF: Coronectomy: A technique to protect the inferior alveolar nerve. Journal of Oral and Maxillofacial Surgery 2004, 62(12):1447-1452.

5. Garcia-Garcia A: Coronectomy: a questionable procedure. J Oral Maxillofac Surg 2005, 63(5):723; author reply 723-724.

6. Cilasun U, Yildirim T, Guzeldemir E, Pektas ZO: Coronectomy in patients with high risk of inferior alveolar nerve injury diagnosed by computed tomography. J Oral Maxillofac Surg 2011, 69(6):15571561.

7. Hatano Y, Kurita K, Kuroiwa Y, Yuasa H, Ariji E: Clinical evaluations of coronectomy (intentional partial odontectomy) for mandibular third molars using dental computed tomography: a case-control study. J Oral Maxillofac Surg 2009, 67(9):1806-1814.

8. Long H, Zhou Y, Liao L, Pyakurel U, Wang Y, Lai W: Coronectomy vs. total removal for third molar extraction: a systematic review. J Dent Res 2012, 91(7):659-665.

9. Renton T, Hankins M, Sproate C, McGurk M: A randomised controlled clinical trial to compare the incidence of injury to the inferior alveolar nerve as a result of coronectomy and removal of mandibular third molars. Br J Oral Maxillofac Surg 2005, 43(1):7-12.

10. Frenkel B, Givol N, Shoshani Y: Coronectomy of the mandibular third molar: a retrospective study of 185 procedures and the decision to repeat the coronectomy in cases of failure. J Oral Maxillofac Surg 2015, 73(4):587-594.

11. Kohara K, Kurita K, Kuroiwa Y, Goto S, Umemura E: Usefulness of mandibular third molar coronectomy assessed through clinical evaluation over three years of follow-up. Int J Oral Maxillofac Surg 2015, 44(2):259-266.

12. Leung YY, Cheung KY: Root migration pattern after third molar coronectomy: a long-term analysis. Int J Oral Maxillofac Surg 2018, 47(6):802-808. 
13. Sedaghatfar M, August MA, Dodson TBJJoo, surgery m: Panoramic radiographic findings as predictors of inferior alveolar nerve exposure following third molar extraction. 2005, 63(1):3-7.

14. Rood JP, Shehab BA: The radiological prediction of inferior alveolar nerve injury during third molar surgery. Br J Oral Maxillofac Surg 1990, 28(1):20-25.

15. Gulicher $D$, Gerlach KL: Sensory impairment of the lingual and inferior alveolar nerves following removal of impacted mandibular third molars. Int J Oral Maxillofac Surg 2001, 30(4):306-312.

16. Ghaeminia H, Meijer G, Soehardi A, Borstlap W, Mulder J, Vlijmen O, Bergé S, Maal TJljoo, surgery m: The use of cone beam CT for the removal of wisdom teeth changes the surgical approach compared with panoramic radiography: a pilot study. 2011, 40(8):834-839.

17. Monaco G, de Santis G, Gatto MR, Corinaldesi G, Marchetti C: Coronectomy: a surgical option for impacted third molars in close proximity to the inferior alveolar nerve. J Am Dent Assoc 2012, 143(4):363-369.

18. Pogrel MA, Lee JS, Muff DF: Coronectomy: a technique to protect the inferior alveolar nerve. J Oral Maxillofac Surg 2004, 62(12):1447-1452.

19. Kouwenberg AJ, Stroy LP, Rijt ED, Mensink G, Gooris PJ: Coronectomy of the mandibular third molar: Respect for the inferior alveolar nerve. J Craniomaxillofac Surg 2016, 44(5):616-621.

20. Gleeson CF, Patel V, Kwok J, Sproat C: Coronectomy practice. Paper 1. Technique and troubleshooting. Br J Oral Maxillofac Surg 2012, 50(8):739-744.

21. Dolanmaz D, Yildirim G, Isik K, Kucuk K, Ozturk A: A preferable technique for protecting the inferior alveolar nerve: coronectomy. J Oral Maxillofac Surg 2009, 67(6):1234-1238.

22. Martin A, Perinetti G, Costantinides F, Maglione MJH, medicine f: Coronectomy as a surgical approach to impacted mandibular third molars: a systematic review. 2015, 11(1):9.

23. Carvalho RW, do Egito Vasconcelos BC: Assessment of factors associated with surgical difficulty during removal of impacted lower third molars. J Oral Maxillofac Surg 2011, 69(11):2714-2721.

24. Winter GB: Principles of exodontia as applied to the impacted mandibular third molar. American Medical Book Company; 1926.

25. de Andrade PF, Silva JNN, Sotto-Maior BS, Ribeiro CG, Devito KL, Assis N: Three-dimensional analysis of impacted maxillary third molars: A cone-beam computed tomographic study of the position and depth of impaction. Imaging Sci Dent 2017, 47(3):149-155.

26. Cohen J: Statistical power analysis for the behavioral sciences: Routledge; 2013.

27. Moreno-Vicente J, Schiavone-Mussano R, Clemente-Salas E, Mari-Roig A, Jane-Salas E, Lopez-Lopez $\mathrm{J}$ : Coronectomy versus surgical removal of the lower third molars with a high risk of injury to the inferior alveolar nerve. A bibliographical review. Med Oral Patol Oral Cir Bucal 2015, 20(4):e508-517.

28. Leung YY, Cheung LK: Long-term morbidities of coronectomy on lower third molar. Oral Surg Oral Med Oral Pathol Oral Radiol 2016, 121(1):5-11.

29. Yeung AWK, Wong NSM, Bornstein MM, Leung YY: Threedimensional radiographic evaluation of root migration patterns 4-8.5 years after lower third molar coronectomy: a cone beam computed 
tomography study. Int J Oral Maxillofac Surg 2018, 47(9):1145-1152.

30. Goto S, Kurita K, Kuroiwa Y, Hatano Y, Kohara K, Izumi M, Ariji E: Clinical and dental computed tomographic evaluation 1 year after coronectomy. J Oral Maxillofac Surg 2012, 70(5):1023-1029.

31. Sutton PR: Migration and eruption of non-erupted teeth: a suggested mechanism. Aust Dent J 1969, 14(4):269-270.

32. Proffit WR, Vig KW: Primary failure of eruption: a possible cause of posterior open-bite. Am J Orthod 1981, 80(2):173-190.

33. Franco S, Vignudelli E, Monaco G, Marchetti C: Influence of secondary wound healing after mandibular third molar coronectomy. Br J Oral Maxillofac Surg 2017, 55(2):145-149.

34. Monaco G, Vignudelli E, Diazzi M, Marchetti C, Corinaldesi G: Coronectomy of mandibular third molars: A clinical protocol to avoid inferior alveolar nerve injury. J Craniomaxillofac Surg 2015, 43(8):1694-1699.

\section{Tables}

\begin{tabular}{|c|c|c|}
\hline Factors & Classifications & Description \\
\hline Age & $\begin{array}{l}\leqq 30 \text { age old } \\
>30 \text { age old }\end{array}$ & \\
\hline Gender & $\begin{array}{l}\text { Male } \\
\text { Female }\end{array}$ & \\
\hline Root number & $\begin{array}{l}2 \text { roots } \\
3 \text { roots }\end{array}$ & \\
\hline $\begin{array}{l}\text { Root } \\
\text { morphology }\end{array}$ & $\begin{array}{l}\text { Convergent } \\
\text { Parallel } \\
\text { Divergent }\end{array}$ & \\
\hline $\begin{array}{l}\text { Success of } \\
\text { coronectomy } \\
\text { cutting }\end{array}$ & $\begin{array}{l}\text { Complete cut } \\
\text { Incomplete } \\
\text { cut }\end{array}$ & $\begin{array}{l}\text { When the sectioned margin of M3 had no undercut to migrate, it means } \\
\text { cutting complete }\end{array}$ \\
\hline $\begin{array}{l}\text { Ramus } \\
\text { relationships }\end{array}$ & $\begin{array}{l}\text { Class I } \\
\text { Class II } \\
\text { Class III }\end{array}$ & $\begin{array}{l}\text { Width between the vertical ascending mandibular ramus and the distal } \\
\text { surface of M2 : Situated anterior (Class I), crown half covered by the } \\
\text { anterior border of ramus (Class II) and crown fully covered by the ramus } \\
\text { (Class III) }\end{array}$ \\
\hline $\begin{array}{l}\text { Impaction } \\
\text { depth }\end{array}$ & $\begin{array}{l}\text { Level A } \\
\text { Level B \& C }\end{array}$ & $\begin{array}{l}\text { Depth of impacted third molar in relation to occlusal plane :Same level } \\
\text { (Level A) or under the occlusal plane (Level B \& C) }\end{array}$ \\
\hline $\begin{array}{l}\text { MD } \\
\text { angulations }\end{array}$ & $\begin{array}{l}\text { Horizontal } \\
\text { Mesial } \\
\text { Vertical \& } \\
\text { Distal }\end{array}$ & $\begin{array}{l}\text { Angle between tangent line on M1 MB cusp and long axis of M3 at sagittal } \\
\text { CBCT section [Appendix figure } 1 \mathrm{~A}]: 0^{\circ}<<15^{\circ} \text { : Horizontal, } 15^{\circ} \leqq<75^{\circ} \text { : } \\
\text { Mesial, } 75^{\circ} \leqq<105^{\circ} \text { : Vertical, } \geqq 105^{\circ}: \text { Distal }\end{array}$ \\
\hline $\begin{array}{l}\text { BL } \\
\text { angulations }\end{array}$ & $\begin{array}{l}\text { Buccal } \\
\text { Lingual }\end{array}$ & $\begin{array}{l}\text { Angle between mid-sagittal line and long axis of } \mathrm{M} 3 \text { at coronal CBCT } \\
\text { section [Appendix figure } 1 \mathrm{~B}]: \geqq-10^{\circ}: \text { Buccal, }<-10^{\circ}: \text { Lingual }\end{array}$ \\
\hline $\begin{array}{l}\text { Contact } \\
\text { point with } \\
\text { M2 \& M3 }\end{array}$ & $\begin{array}{l}\text { Crown } \\
\text { Root }\end{array}$ & Level of point when M3 was contacted with or adjacent to M2 \\
\hline
\end{tabular}

Table 1. Classifications and description of patient's demographic data and analysis factors 


\begin{tabular}{|c|c|c|c|c|}
\hline Factors & Classifications & $\mathrm{N}(\%)$ & $\operatorname{Exp}(B)$ & 95\% CI Sig.** \\
\hline Age & $\begin{array}{l}\leqq 30 \text { age old } \\
>30 \text { age old }\end{array}$ & $\begin{array}{l}23(69.7) 0.899 \\
10(30.3)\end{array}$ & 0.088 & 0.0051 .4820 .092 \\
\hline Gender & $\begin{array}{l}\text { Male } \\
\text { Female }\end{array}$ & $\begin{array}{l}11(33.3) 0.730 \\
22(66.7)\end{array}$ & & \\
\hline Root number & $\begin{array}{l}2 \text { roots } \\
3 \text { roots }\end{array}$ & $\begin{array}{l}23(69.7) 0.516 \\
10(30.3)\end{array}$ & 75.48 & 0.8067065 .80 .062 \\
\hline Root morphology & $\begin{array}{l}\text { Convergent } \\
\text { Parallel } \\
\text { Divergent }\end{array}$ & $\begin{array}{l}12(36.4) 0.954 \\
14(42.4) \\
7(21.2)\end{array}$ & $\begin{array}{l}1.243 \\
0.008\end{array}$ & $\begin{array}{l}0.07620 .2460 .879 \\
0.0000 .5720 .027^{* * *}\end{array}$ \\
\hline Success of coronectomy cutting & $\begin{array}{l}\text { Complete cut } \\
\text { Incomplete cut }\end{array}$ & $\begin{array}{l}15(45.5) 0.085 \\
18(54.5)\end{array}$ & 68.67 & $1.7292727 .50 .024 * * *$ \\
\hline Ramus relationships & $\begin{array}{l}\text { Class I } \\
\text { Class II } \\
\text { Class III }\end{array}$ & $\begin{array}{l}18(54.5) 0.974 \\
15(45.5) \\
0(0.0)\end{array}$ & & \\
\hline Impaction depth & $\begin{array}{l}\text { Level A } \\
\text { Level B \& C }\end{array}$ & $\begin{array}{l}26(78.8) 0.835 \\
7(21.2)\end{array}$ & 0.031 & $0.0010 .9390 .046^{* * *}$ \\
\hline MD angulations & $\begin{array}{l}\text { Horizontal } \\
\text { Mesial } \\
\text { Vertical \& Distal }\end{array}$ & $\begin{array}{l}10(30.3) 0.511 \\
5(15.2) \\
18(54.5)\end{array}$ & $\begin{array}{l}0.001 \\
0.079\end{array}$ & $\begin{array}{ll}0.0000 .279 & 0.016^{* * *} \\
0.0041 .628 & 0.100\end{array}$ \\
\hline BL angulations & $\begin{array}{l}\text { Buccal } \\
\text { Lingual }\end{array}$ & $\begin{array}{l}28(84.8) 0.002^{* *} \\
5(15.2)\end{array}$ & & \\
\hline $\begin{array}{l}\text { Contact point with } \\
\text { M2 \& M3 }\end{array}$ & $\begin{array}{l}\text { Crown } \\
\text { Root }\end{array}$ & $\begin{array}{l}9 \text { (27.3) } 0.346 \\
24(72.7)\end{array}$ & & \\
\hline
\end{tabular}

Table 2. Univariate and binary logistic regression of two-dimensional analysis

The migration distance using two-dimensional analysis method was measured by the differences between the trace of lamina dura and the present lamina dura of apical apex at the 6 months' periapical radiographs. It was measured 2 times and the average distance was recorded. If the migration distance was over $2 \mathrm{~mm}$, we classified that case as ' 2 dimensionally migrated group' and if was not, we classified it as '2 dimensionally not migrated group'.

$\mathrm{CI}=$ Confidence interval

* = Significance is calculated by t-test, ANOVA, according to the characteristics of factors

** $=$ Significance is calculated by binary logistic regression

$* * *=$ statistically significant differences $(\mathrm{p}<0.05)$

Nagelkerke R-square: 0.543, P: 0.034 


\begin{tabular}{|c|c|c|c|c|c|}
\hline Factors & Classifications & Mean (SD) & Sig.* & $\bar{B}$ & Sig.** \\
\hline Age & $\begin{array}{l}\leqq 30 \text { age old } \\
>30 \text { age old }\end{array}$ & $\begin{array}{l}23(69.7) 4.13(1.58) \\
10(30.3) 4.06(1.38)\end{array}$ & 0.446 & & \\
\hline Gender & $\begin{array}{l}\text { Male } \\
\text { Female }\end{array}$ & $\begin{array}{l}11(33.3) 3.98(1.28) \\
22(66.7) 4.17(1.62)\end{array}$ & 0.288 & & \\
\hline Root number & $\begin{array}{l}2 \text { roots } \\
3 \text { roots }\end{array}$ & $\begin{array}{l}23(69.7) 3.99(1.33) \\
10(30.3) 4.37(1.90)\end{array}$ & 0.617 & & \\
\hline Root morphology & $\begin{array}{l}\text { Convergent } \\
\text { Parallel } \\
\text { Divergent }\end{array}$ & $\begin{array}{c}12(36.4) 4.20(1.01) \\
14(42.4) 4.10(1.11) \\
7(21.2) 3.97(2.73)\end{array}$ & 0.598 & & \\
\hline Success of coronectomy cutting & $\begin{array}{l}\text { Complete cut } \\
\text { Incomplete cut }\end{array}$ & $\begin{array}{l}15(45.5) 3.70(1.45) \\
18(54.5) 4.60(1.45)\end{array}$ & 0.265 & & \\
\hline Ramus relationships & $\begin{array}{l}\text { Class I } \\
\text { Class II } \\
\text { Class III }\end{array}$ & $\begin{array}{l}18(54.5) 4.10(1.60) \\
15(45.5) 4.12(1.43) \\
0(0.0)\end{array}$ & 0.265 & & \\
\hline Impaction depth & $\begin{array}{l}\text { Level A } \\
\text { Level B \& C }\end{array}$ & $\begin{array}{c}26(78.8) 4.14(1.60) \\
7(21.2) 4.00(1.15)\end{array}$ & 0.209 & & \\
\hline MD angulations & $\begin{array}{l}\text { Horizontal } \\
\text { Mesial } \\
\text { Vertical \& Distal }\end{array}$ & $\begin{array}{c}10(30.3) 4.54(2.07) \\
5(15.2) 4.19(1.28) \\
18(54.5) 3.85(1.18)\end{array}$ & 0.506 & 1.855 & $0.008 * * *$ \\
\hline BL angulations & $\begin{array}{l}\text { Buccal } \\
\text { Lingual }\end{array}$ & $\begin{array}{c}28(84.8) 3.78(1.16) \\
5(15.2) 5.96(1.96)\end{array}$ & 0.422 & -1.540 & $0.004^{* * *}$ \\
\hline $\begin{array}{l}\text { Contact point with } \\
\text { M2 \& M3 }\end{array}$ & $\begin{array}{l}\text { Crown } \\
\text { Root }\end{array}$ & $\begin{array}{rr}9(27.3) & 4.68(0.84) \\
24(72.7) & 3.93(1.67)\end{array}$ & 0.556 & & \\
\hline $\begin{array}{l}\mathrm{X} \text {-axis variations } \\
(\mathrm{X} \square-\mathrm{X} \square)\end{array}$ & & $0.26(1.87)$ & $0.004^{* * *}$ & & \\
\hline $\begin{array}{l}\text { Y-axis variations } \\
(y \square-y \square)\end{array}$ & & $-2.67(2.13)$ & $0.001 * * *$ & -0.582 & $20.000 * * *$ \\
\hline $\begin{array}{l}\text { Z-axis variations } \\
(\mathrm{z} \square-\mathrm{z} \square)\end{array}$ & & $1.23(1.63)$ & 0.089 & & \\
\hline
\end{tabular}

\section{Table 3. Univariate and multivariate linear regression of three-dimensional analysis}

The migration distance using three- dimensional analysis method was calculated by the differences between the coordinates at preoperation $\left(\mathrm{X}_{1}, \mathrm{Y}_{1}, \mathrm{Z}_{1}\right)$ and at the 6months after coronectomy $\left(\mathrm{X}_{2}, \mathrm{Y}_{2}, \mathrm{Z}_{2}\right)$. It means how far were roots migrated from the preoperation position. The table shows the distribution of the three-dimensional analysis cases and the mean average migration distance according to the various factors. Also it shows the correlation between average migration distance and each $\mathrm{X}, \mathrm{Y}, \mathrm{Z}$ variations which implies that movement toward specific axes affect the direction of root's movement.

$\mathrm{SD}=$ standard deviation

* = Significance is calculated by t-test, ANOVA and correlation analysis, according to the characteristics of factors

** = Significance is calculated by multivariate linear regression

$* * *=$ Statistically significant differences $(\mathrm{p}<0.05)$

R square: 0.655, P: 0.000 


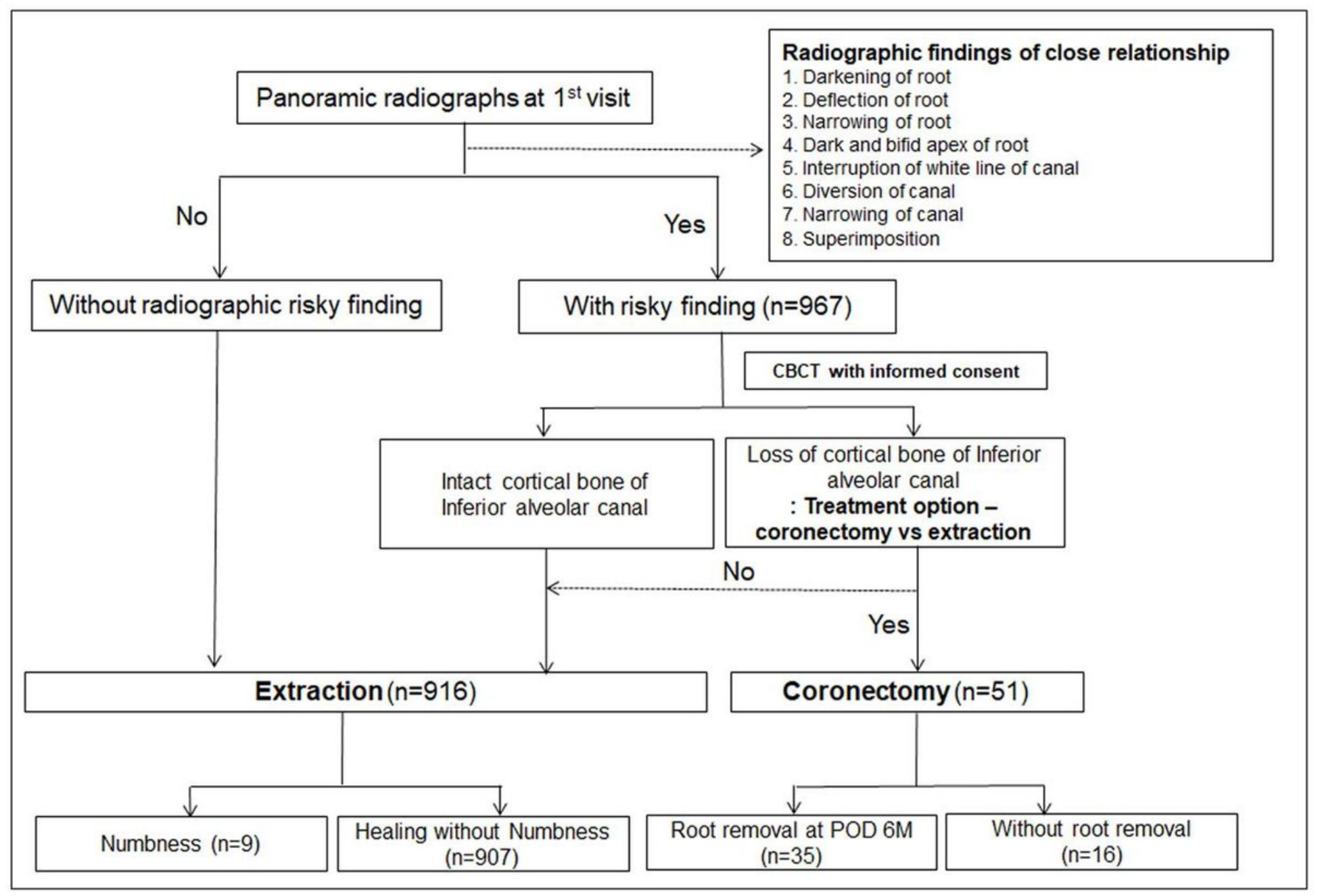

Figure 1

Overview of clinical study 


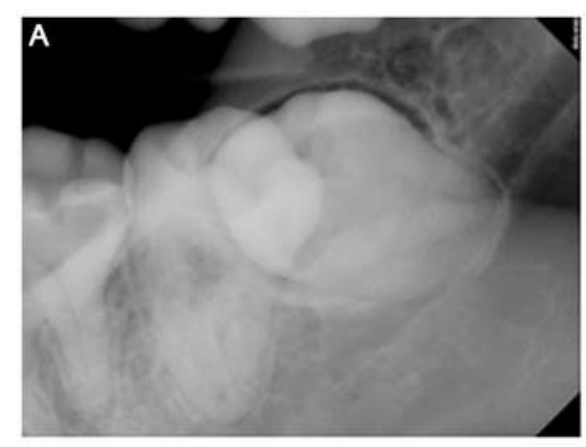

D

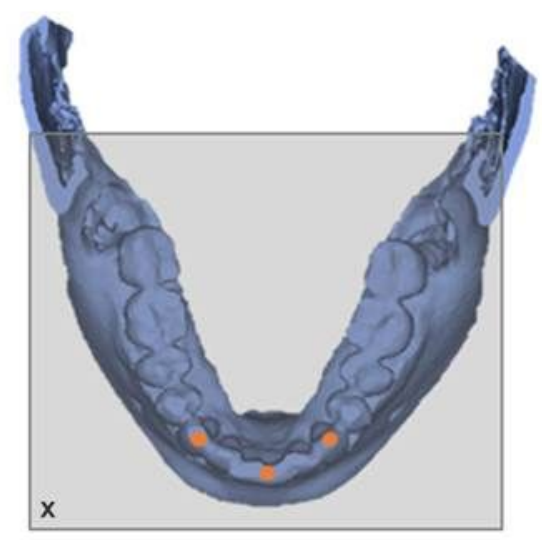

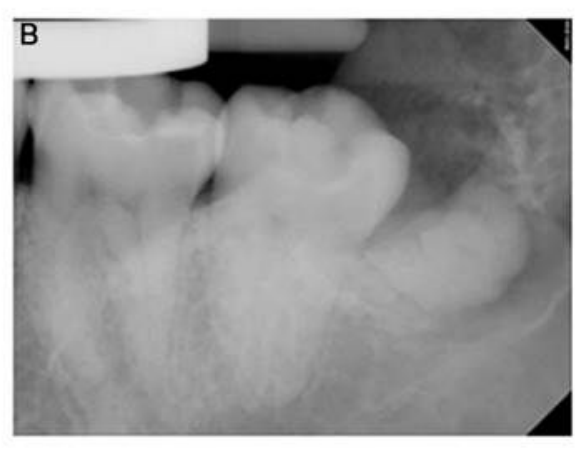

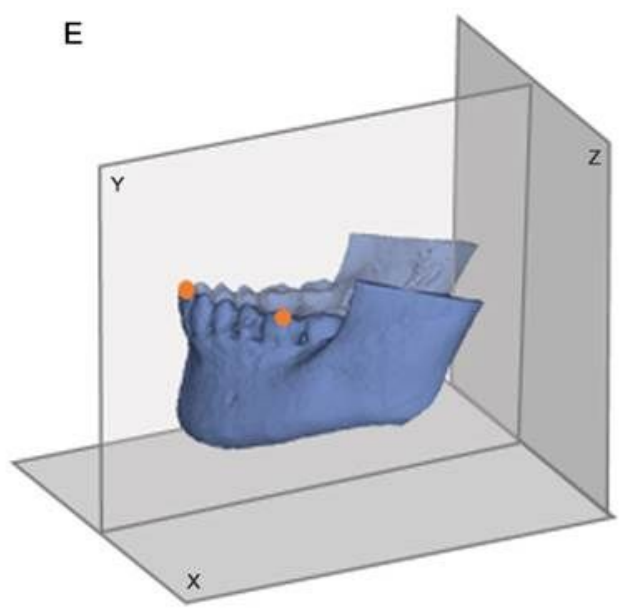

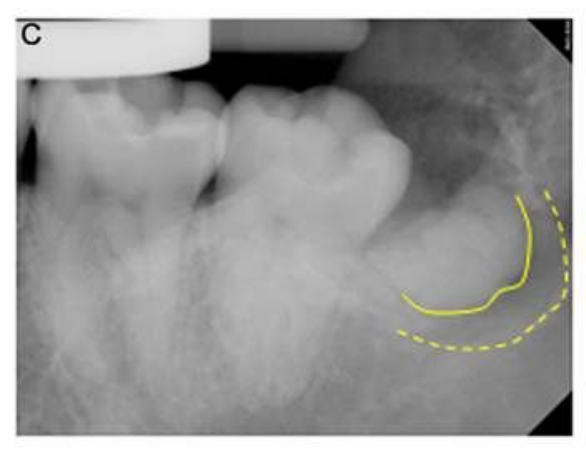

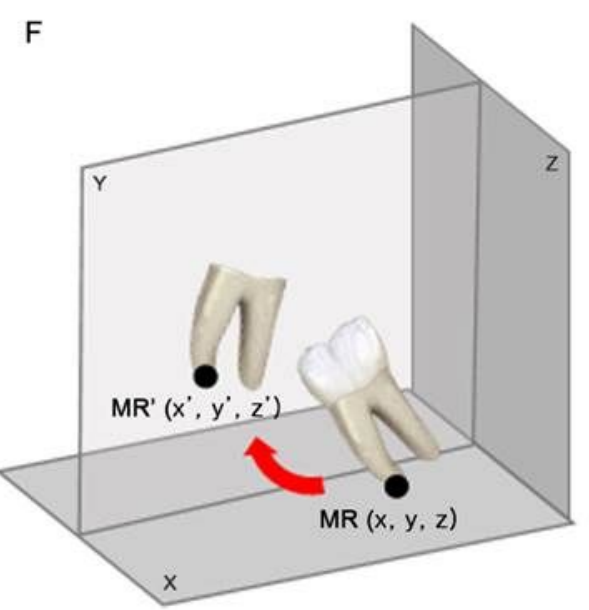

\section{Figure 2}

Analysis methods. A lamina dura of apical apex was observed on the periapical radiograph taken at the preoperation (A) and 6 months after coronectomy (B). We measured the distance between the trace of lamina dura at the preoperation ( $C$, dotted line) and that of present ( $C$, full line). $D$ and $E$ show how axes are set using anatomical reference points in 3 dimensionally. Interincisal tip and both canine tips are used to set X-axis (D) and interincisal tip and mesiobuccal cusp tip of mandibular first molar are used to set $\mathrm{Y}$ axis (E). The root migration after coronectomy was schematically represented by 3 dimensional coordinates (F). *MR: mesial root apex at preoperation MR': mesial root apex at 6 months after coronectomy

\section{Supplementary Files}

This is a list of supplementary files associated with this preprint. Click to download.

- Supplemental200630.docx 